\title{
A STUDY ON THE EFFECTS OF LAND USE CHANGE ON FLOODING RISKS IN NIGERIA
}

\author{
Eseosa Halima IGHILE ${ }^{1}$ (D), Hiroaki SHIRAKAWA ${ }^{2}$
}

DOI: $10.21163 / G T \_2020.151 .08$

\begin{abstract}
:
This paper aims at identifying the drivers of land use change and their effects on flood risks in Nigeria. The study presumed that changes to land use and their drivers could affect the level of risks to natural disasters. From the research; we identified the factors responsible for land use changes in Nigeria between 2000 and 2013 and their effects on the level of flooding risks. The multinomial logistic regression models the probability of land use changes and their impact on flooding risks, as a function of explicit independent variables. The results show that Economic, biophysical, demographic and climatic variables were the significant determinants of land use change. Additionally, while assessing the relationship between the changes in land use and flood risks, agricultural, settlement and forest land use had the most significant contributions to the changes in the level of flood risks. The result of this study would aid in the contribution and improvement of efficient countermeasures for flooding disasters. Therefore ensuring the prioritisation of the flood hazard areas and future land development.
\end{abstract}

Key-words: Land use, Flood Risks, Regression, Nigeria.

\section{INTRODUCTION}

Nigeria, in the last 40 years, has witnessed significant changes in land-use/land cover(LULC) across various regions due to both natural and human-made factors. These changes have occurred in the areas of infrastructural development, resource extraction, crop cultivation, and human development. As continuous land use changes are one of the prominent attributes of a developing country (Meyer \& Turner, 2003), like Nigeria; due to its rapid urbanisation, population growth, increased inflow of population to urban centres, climate change and the frequent modification by both natural and anthropogenic factors (Peter et al., 2012).

Aside the changes to land use, the frequent occurrence of flooding disasters in Nigerian cities have become a major social, economic and environmental problem which has greatly affected the overall functioning of the urban environment (Bashir et al., 2012). Moreover, over the years, this has forced millions from their homes, wrecked businesses, contaminated water resources and amplified the risk of diseases (Baiye, 1988, Akinyemi, 1990; Nwaubani, 1991; Edward-Adebiyi, 1997, UNECA, 2015). Over time, these changes and amplified pressure on land and the frequent occurrence of disasters has affected the socioecological resilience of the country (Baiye, 1988, Akinyemi, 1990; Nwaubani, 1991; Edward-Adebiyi, 1997, UNECA, 2015). Furthermore, the lack of the relevant management plans to respond effectively to disasters, and with the ever-growing possibility that each

\footnotetext{
${ }^{1}$ Nagoya University, Graduate School of Environmental Studies, Environmental Engineering and Architecture,464-8601, Nagoya, Japan,ighileeseosal @gmail.com;

${ }^{2}$ Nagoya University, Graduate School of Environmental Studies, Environmental Engineering and Architecture, 464-8601, Nagoya, Japan.sirakawa@urban.env.nagoya-u.ac.jp
} 
change to the existing land use having the likelihood of altering the ability of ecosystem services to function and combat impending disasters (Khan et al., 2014). Efforts to understand the role of land-use, its drivers and their relationship to flooding disaster risks and management are now necessary. Therefore, estimating and understanding what drives the changes to land use is crucial for the sustainable growth, management and development of Nigeria. Similarly, assessing the contribution of each land use class to changes in flooding disaster risks levels is vital for a practical land resource, disaster management, and mitigation against the underlying vulnerability of human systems. Asides having proper knowledge on the drivers and contributions of the changes to land use on disaster risks, this study would assist in enabling the creation of appropriate land use-land cover plans which focuses on mitigating the impacts of each environmental stressor on disaster risks. This study also aims at enumerating the drivers of LULC change, and the contributions of each historical LULC class to the increased risk of disasters for the affected areas. The purpose of this study firstly is to investigate the main drivers of land-use change using analytical modelling techniques. Secondly, analyse the relationship and impacts of the changes in the LULC types and their drivers on flood disaster risks in Nigeria.

\section{STUDY AREA}

The Federal Republic of Nigeria is in Western Africa (Fig. 1). It occupies an area of 923,768 sq.km, including the land surface area of about 910,770 sq.km, and the maritime area covering approximately 200 nautical miles. Nigeria consists of 36 states, and the federal capital territory Abuja.

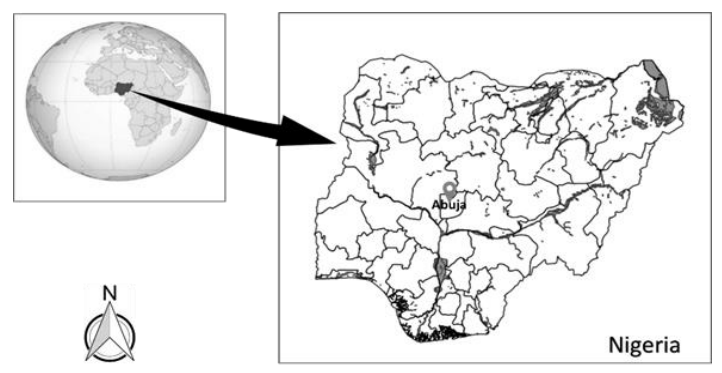

Fig. 1. Geographical Location of Nigeria (Source of data: Authors)

The population of Nigeria is approximately 190 million (UN,2017), with about $48.6 \%$ of the entire population living in urban areas distributed across eleven(11) cities having a population above a million $(1,000,000)$ residents and more than 70 cities having over one hundred thousand $(100,000)$ inhabitants (USGS, 2015). The significant contributions to the Nigerian economy is attributed to different sectors; Agriculture (21.65\%), Trade (17.06\%), Information \& Communication (12.41\%), Manufacturing (9.91\%), Mining \& Quarrying (9.67\%), Oil (9.61\%), Real Estate Services (5.63\%), Construction (4.04\%), Finance \& Insurance (3.55\%), Professional, Scientific \& Technical Services (3.51\%), (World Bank, 2017). Even as Nigeria continues to experience major economic growth, with a GDP of about 500 billion US dollars in 2015 (National Bureau of statistics, 2017), a large number of citizens in Nigeria still live in abject poverty. The dynamics of wealth 
distribution in Nigeria according to the world poverty clock indicates that the level of inequality in Nigeria is at a record high, with about $46.5 \%$ of the total population are living in multidimensional /extreme poverty (world poverty clock,2018).

The trends in land use in Nigeria between the period 1975 and 2013 shows that there have been significant changes to the land use types in Nigeria. Agriculture, settlement and forest land use, have undergone the most noteworthy changes. The total area of agricultural land use experienced a massive increase from about 21 per cent in 1975 to 41 per cent in 2013, of the entire land territory (Fig. 2). That is, the area initially covered by agricultural land use increased from about 192,000 square kilometres to 379,000 square kilometres. The implication of this massive change indicates that agricultural land use conversion doubled within thirty-eight years. Apart from the rapid agricultural land use expansion, settlements land use also experienced enormous growth from an estimated average of 1-2 per cent per annum between 1975 and 2000 to a rate of 2-4 per cent between 2000 and 2013. Subsequently, although agricultural and settlement land use shows an increase in the land coverage area, forest land use, on the other hand, decreased by about 45 per cent between the period 1975 and 2013.

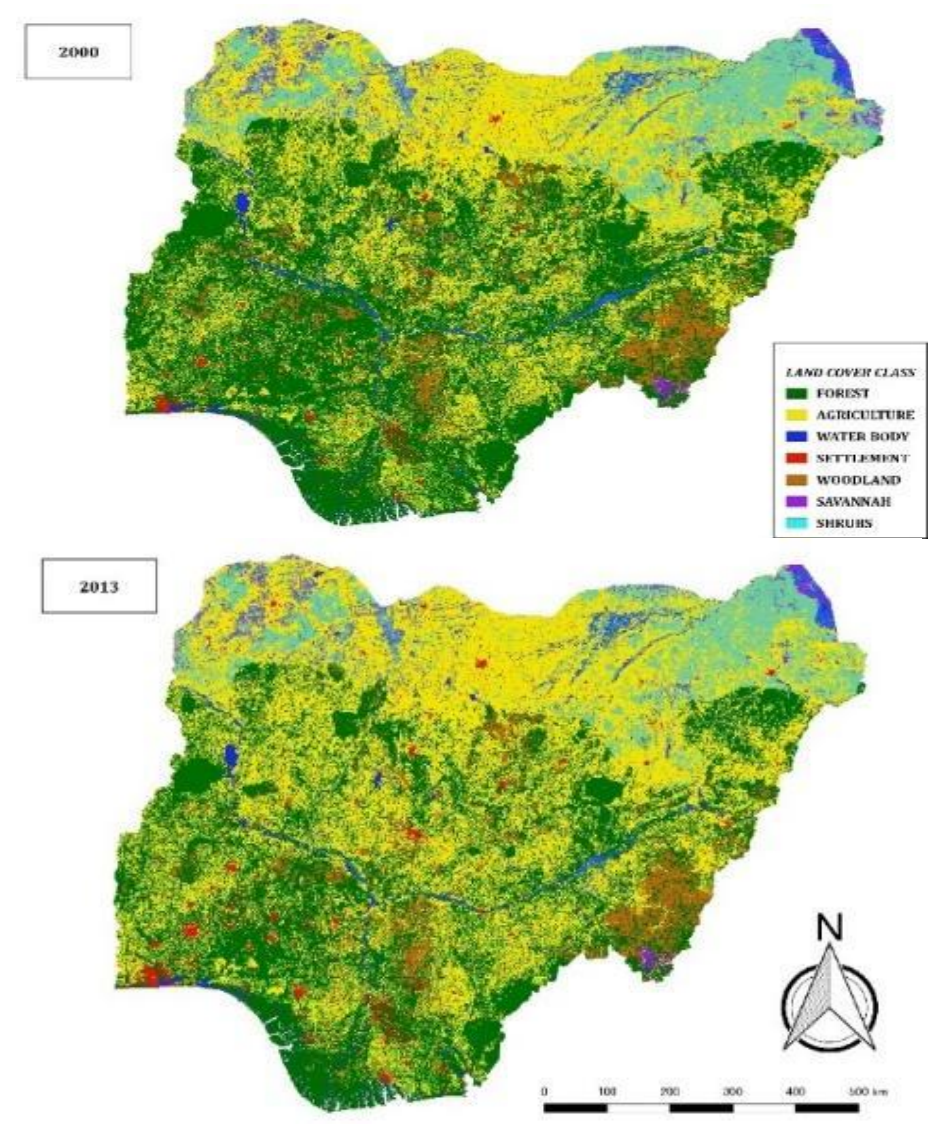

Fig. 2. Land use maps of Nigeria (2000 and 2013) (Source of data: USGS,2015) 
Nigeria frequently experiences flooding incidents, especially during the peak summer months between June and August, which is the most predominant natural disaster event in Nigeria (Olorunfemi \& Adebimpe, 2011). The trend in disaster occurrence across the country can be observed, in most of the large and densely populated areas and neighbouring regions having a higher frequency of disasters. The observed reason for the increased reoccurrence of flooding incidents in Nigeria's major urban centres results from the increased influx of new residents into the major cities, the high population growth and population density. Aside from the increased migration to urban centres, the limited arable land for human settlement has resulted in overcrowding, slum formation, increased pollution. The increase experienced in the level of uncontrolled and unsustainable land use conversions, when combined with the existing flood hazards, potentially increases the risk to urban flooding disasters (Oladokun \& Proverbs, 2016).

\section{METHODOLOGY AND DATA}

\subsection{Modelling the Drivers of Land Use Change}

We assessed the drivers of land use change in Nigeria with the aid of the multinomial logistic regression, to model the probability of land use conversion as a function of various selected independent variables. According to Suwarno et al. (2019), several factors can be used to understand the impacts of each driver such as the geologic, hydrologic, biologic, climatologic, geographic, social, economic, and technologic characteristics when modelling probabilistic changes. In the study, the variable selection for the land use model was chosen based on several factors, such as economic, biophysical, demographics, climatic and accessibility, which influence land use pattern formation (Kim \& Heung, 2016). The selection of the multinomial logistic regression model for this research aids in determining the patterns and factors for each land use class and their response due to several social, economic and environmental interactions. We analysed the land use maps of two separate years 2000 and 2013 respectively. The equation for the land use probability ( $\pi \mathrm{ij}$ ) is;

$$
\pi_{i j}=\frac{\exp \left(x_{i} \beta_{j}\right)}{\sum_{k=1}^{J} \exp \left(x_{i} \beta_{k}\right)} j=1, \ldots, J
$$

where;

$\mathrm{i}$ : index of the location.

$\boldsymbol{\pi}_{\boldsymbol{i} \boldsymbol{j}}$ : the probability of $\mathrm{j}$ at 1

$\mathrm{j}$ : type of LULC

$\beta$ : vector of parameters

$\boldsymbol{x}$ : vector of variables

$k$ : index of the hazard risk level

$J$ : total number of LULC types

For the assessment of the index of the hazard risk level used in the land use model, the existing flood risk data from the UNEP study (2011) classified into five categories; low, low/medium, medium, high and extreme using GIS (Fig.3), and further calculated the percentage of each risk level under each land use type. The risk level is classified based on the magnitude of the total number of persons affected in the event of a flooding incident. The purpose of the classification is to rank the risk levels based on the severity scale that would allow for an understanding of the areas most affected by flooding disasters (Klemešová et al., 2014). 


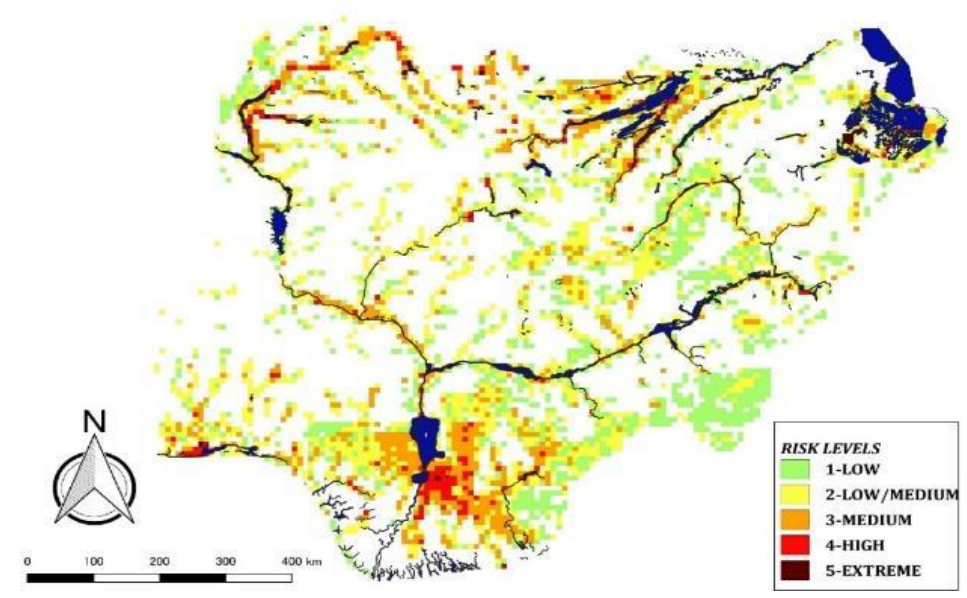

Fig. 3. Multilevel Hazard risk classification in Nigeria (Source of data: UNEP, 2011)

\subsection{Data}

This study utilised an extensive range of datasets. The type and nature of the data used include both temporal and spatial resolutions comprising of land use maps, and other datasets categorised under climatic, biophysical, neighbourhood, demographics and economics respectively. The pre-processed land use maps for the period 2000 and 2013, were obtained from the United States Geological Survey (USGS,2015), digital elevation model (DEM) with a resolution of $30 \times 30 \mathrm{~m}$, downloaded from the STRM30 (https://earthexplorer.usgs.gov/). The soil datasets were classified into seven categories (N1-N7) to represent the seven major categories of soil types in Nigeria, including the proportions of sand, silt, loamy and clay, and the soil depths extracted from the Harmonized World Soil Database version 1.2 (HWSD) (Nachtergaele et al., 2009). Demographic information consisting of Population density is from LandScan, which is the global population distribution data made by ORNL. The sociological data such as migration and the economic variable: gridded Gross Regional Product (GRP) (in US\$) and poverty ratio, downloaded from, http://sedac.ciesin.columbia.edu/data/set/spatialecongecon-v4 (2005 and 2010). Climatic data, including annual average temperature, and precipitation obtained from the GPCC Global Precipitation Climatology Centre at https://www.esrl.noaa.gov/psd/data/gridded/data.gpcc.html). Flood risks maps are from the United Nations Environment Programme; http://www.grid.unep.ch (UNISDR, UNEP,2011, \& Umvoto Africa, 2004). The neighbourhood indices; calculated from randomly generated points, and the other datasets, such as the official administrative maps, were obtained from GADM (https://gadm.org/).

\subsubsection{Analysis}

The data used for the regression analysis is through the generation of 10000 randomly generated points within the Nigeria administrative boundary map, and each point sampled off the selected independent variables in the QGIS environment. The extracted data from each location is then processed, first by correlation analysis to eliminate variables that are closely correlated from the model to ensure good results. All the statistical analytical computations are in the $r$ studio environment. The Likelihood-ratio (LR), then compares the log-likelihood from the model with that of the reduced model ignoring the explanatory 
variables. In this case, the multinomial logistic regression models of multi-dimensional conversions for settlements, agricultural and forest land use types during the periods of 2000-2013, is used to determine the pattern and factors responsible for the changes in land use cover change. The model significance is at 5\%. A back-step approach is applied during the final model calibration process to assign only variables with importance in the final regression results.

\section{RESULTS AND DISCUSSIONS}

\subsection{Drivers of Land Use Change}

\subsubsection{Agricultural Land Use}

Table 1 shows the result of the regression analysis for the drivers of agricultural land use and the probability of agricultural land use. The results indicate that population density, temperature, the rate of internal migration, precipitation, poverty, distance to water bodies, soil quality and the GRP per capita, have a positive impact on the probability of conversion to agricultural land. That is; with a unit change in any of those above, there is a high likelihood of the changes to the land use type around the surrounding and existing land cover class would be agricultural. On the other hand, elevation, distance from the road, and distance from the railway line, all have negative coefficients on the probability of agricultural land use conversion. The negative values show that; they do not influence the likelihood of agricultural land conversion.

Table 1.

Multinomial Logistic Regression for the probability of Agricultural Land ( $n=10000)$.

\begin{tabular}{lllll}
\hline Variables & Estimate & $\begin{array}{l}\text { Standard } \\
\text { Error }\end{array}$ & $\begin{array}{l}\mathbf{Z} \\
\text { Value }\end{array}$ & $\begin{array}{l}\text { Significant } \\
\text { Probability (pr>[z] })\end{array}$ \\
\hline Population density & 7.37 & 1.67 & 4.41 & $1.03 * * *$ \\
Elevation & -6.34 & 1.47 & -4.31 & $1.60 * * *$ \\
Gross Regional Product & 7.11 & 2.63 & 2.71 & $0.01 * *$ \\
Railway & -1.75 & 6.23 & -2.81 & $0.01 * *$ \\
Temperature & 9.82 & 7.89 & 12.44 & $0.00 * * *$ \\
Road & -1.61 & 1.56 & -10.26 & $0.00 * * *$ \\
migration & 5.94 & 1.03 & 5.79 & $7.22 * * *$ \\
Precipitation & 3.43 & 7.45 & 4.61 & $4.05 * * *$ \\
Poverty & 6.67 & 9.21 & 7.24 & $4.37 * * *$ \\
Water & -1.38 & 8.45 & -0.16 & $0.87 *$ \\
Soil quality & 5.24 & 1.42 & 0.37 & 0.71 \\
Soil N1(1 if yes, otherwise 0) & 3.26 & 7.17 & 4.54 & $5.62 * * *$ \\
type N2(1 if yes, otherwise 0) & 1.76 & 4.47 & - & - \\
$\quad$ N3(1 if yes, otherwise 0) & -1.25 & 6.23 & -2.00 & $0.05 *$ \\
$\quad$ N4(1 if yes, otherwise 0) & -3.11 & 9.94 & -3.13 & $0.00 * *$ \\
$\quad$ N5(1 if yes, otherwise 0) & 2.60 & 8.30 & 3.13 & $0.00 * *$ \\
$\quad$ N6(1 if yes, otherwise 0) & -3.55 & 1.02 & -3.48 & $0.00 * * *$ \\
$\quad$ N7(1 if yes, otherwise 0) & -6.30 & 1.13 & -5.56 & $2.66 * * *$ \\
Low risk & -2.01 & 4.15 & -0.48 & 0.63 \\
Medium risk & -1.65 & 4.16 & -0.40 & 0.69 \\
\hline
\end{tabular}

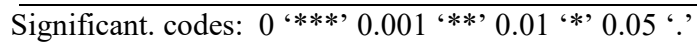


The results explain that the higher the poverty ratio (Table 1), the higher the likelihood of agriculture production as a source of revenue, leading to agriculture land expansion. Migration with a positive coefficient (Table 1) for agriculture land use change explains that as the rate of movement from rural to urban areas continues to increase, the demand for agricultural products in the urban centres will continue to grow. Additionally, the result explains the income (economic character) is also a key driver of agricultural land use change. The phenomenon will require more agriculture land conversion around urban settlements and a reduction in the productivity of some of the existing agricultural land in rural areas due to the low labour force.

\subsubsection{Settlement Land Use}

The results (Table 2) show that Population density, Elevation, Gross Regional Product, temperature, internal migration, distance to water bodies and soil quality, have positive coefficients on the likelihood of settlement land use change. Of the seven variables that positively influence settlement land use changes, population density, the Gross Regional Product, and temperature have the most significant impact on settlement land use change ( $p>0.05)$. On the other hand, poverty ratio, precipitation, distance from the road, distance from the railway line and the population density, gives a negative estimate value or the probability of settlement land use change. The rate of migration, gross regional product) and elevation is an indication that the drivers of settlement land use change, result from a combination of both demographics, economic and biophysical characteristics.

Table 2.

Multinomial Logistic Regression for the probability of settlement Land Use ( $n=10000)$.

\begin{tabular}{lllll}
\hline Variables & Estimate & $\begin{array}{l}\text { Standard } \\
\text { Error }\end{array}$ & $\begin{array}{l}\text { Z } \\
\text { Value }\end{array}$ & $\begin{array}{l}\text { Significant Probability } \\
(\mathrm{pr}>[\mathrm{z}])\end{array}$ \\
\hline Population density & 1.28 & 2.14 & 5.99 & $2.12 * * *$ \\
Elevation & 7.96 & 4.38 & 1.82 & 0.07 \\
Gross Regional Product & 1.34 & 3.00 & 4.45 & $8.43 * * *$ \\
Railway & -2.14 & 2.35 & -0.91 & 0.36 \\
Temperature & 1.68 & 2.35 & 7.18 & $7.19 * * *$ \\
Road & -2.61 & 7.02 & -3.72 & $0.00 * * *$ \\
migration & 6.55 & 3.33 & 0.20 & $0.84 * * *$ \\
Precipitation & -3.59 & 2.08 & -1.73 & $0.08 *$ \\
Poverty & -1.72 & 2.36 & -7.29 & $3.10 * * *$ \\
Water & 4.04 & 2.26 & 0.18 & $0.86 *$ \\
Soil quality & 2.94 & 3.38 & - & - \\
Soil N1(1 if yes, otherwise 0) & 3.27 & 9.70 & 3.38 & $0.00 * * *$ \\
type N2(1 if yes, otherwise 0) & 1.75 & 4.47 & 0.04 & 0.97 \\
$\quad$ N3(1 if yes, otherwise 0) & -1.37 & 1.15 & -1.19 & 0.23 \\
$\quad$ N4(1 if yes, otherwise 0) & -1.29 & 7.31 & -1.76 & 0.08 \\
$\quad$ N5(1 if yes, otherwise 0) & 4.87 & 2.55 & 1.91 & 0.06 \\
$\quad$ N6(1 if yes, otherwise 0) & -1.86 & 1.02 & -1.82 & 0.07 \\
$\quad$ N7(1 if yes, otherwise 0) & -2.60 & 3.97 & -0.66 & 0.51 \\
Low risk & -9.49 & 5.40 & -1.76 & 0.08 \\
Medium risk & -1.10 & 5.52 & -1.99 & $0.05 *$ \\
\hline
\end{tabular}

Significant. codes: 0 ‘***’ $0.001^{\text {'**’ }} 0.01^{\text {‘*’ }} 0.05^{\prime}$ '’ 
In the results in Fig. 4, we can easily understand how each of the selected drivers affects the probability of each respective land use class. Fig. 4 explains when a change occurs in one variable and all other variables been held constant. The results show that; with an increase in the population density (Fig. 4a), we can observe that settlement land use continues to grow and whereas, the probability of agricultural and forest land conversion diminishes. GDP (Fig. 4b) also plays a vital role in land use conversion.
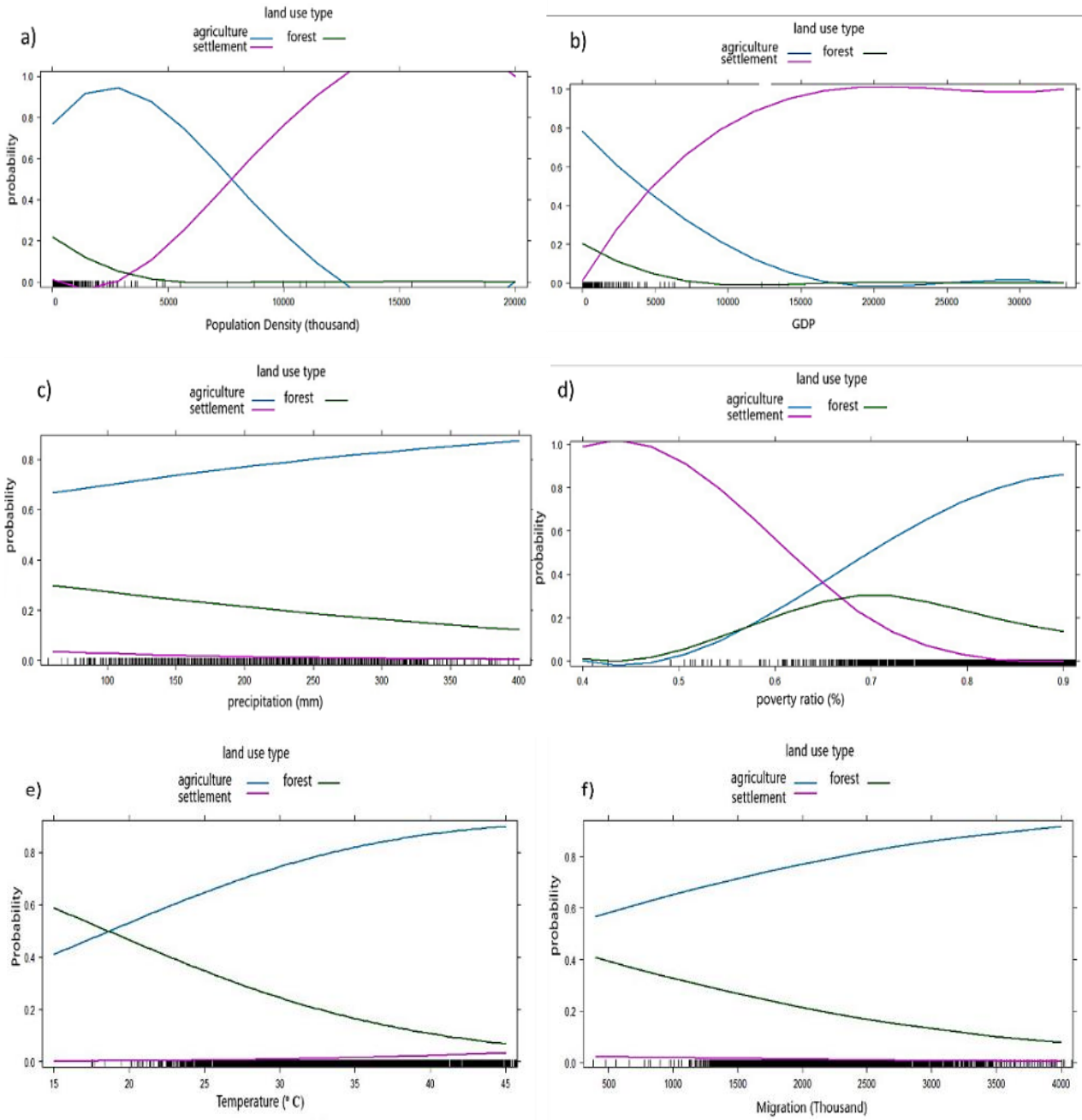

Fig. 4. The effects of the drivers of land use change a) population density, b) GDP, c), precipitation d), poverty ratio e) temperature and f) migration.

The higher the GDP, the higher the rate of settlement conversion, and while the GDP falls under $\$ 5000$, the observed trend is that there is an increased probability of agriculture land expansion. In contrast, forest land declines due to agriculture land expansion. As income is perceived to play a vital role in the development of any society, we can equally compare the trend in income growth, with the growth rate of poverty. However, for 
precipitation (Fig. 4c), there is a minimal impact on the changes experienced in land use. On the other hand, with every other variable been constant while a change occurs in the poverty ratio, we can notice that as the percentage of the total population in poverty rises (Fig. 4d), so does agricultural land increase, forestry and settlement expansion declines rapidly. The reason for this phenomenon is because an increase in poverty levels would lead to more individuals engaging in primary production to cater for their basic needs, and less focus is on infrastructural development (Meyer \& Turner, 2003). For the case of the climatic variables, increasing temperature levels would lead to the further expansion of agricultural land areas and a decline in forest cover an indirect impact of climate change.

\subsection{Percentage distribution of land use class in each risk zone}

Fig. 5 explains the results of the percentage distribution of each land use class in each risk level zone. According to (Furtună \& Holobâcă, 2013), the benefit of the risk probability analysis assists in comparing the current information on land use around each risk zone. In the low-risk zones, agriculture land use takes the largest share of $59.3 \%$, while the settlement is set at $0.8 \%$ and forest $39.8 \%$ respectively. The same trend in agriculture land use is possessing the largest share in each risk zone $(61.8 \%$ in low/medium, $70.2 \%$ in medium and $59.8 \%$ in the high risk) level zones, respectively. In the case of settlement land use, for the low to medium risk zones, the percentage distribution falls between $0.8-2.5 \%$ respectively. However, for the high and extreme risk levels, settlement land use tends to have a more considerable margin in the distributive scale falling between 14.6 and $66.7 \%$ respectively. The indication is that the settlement land areas are mostly in the high and extremely high-risk zones, which may increase the mortality ratio and overall damage to the socio-economic dynamics of Nigeria in the event of a natural disaster.

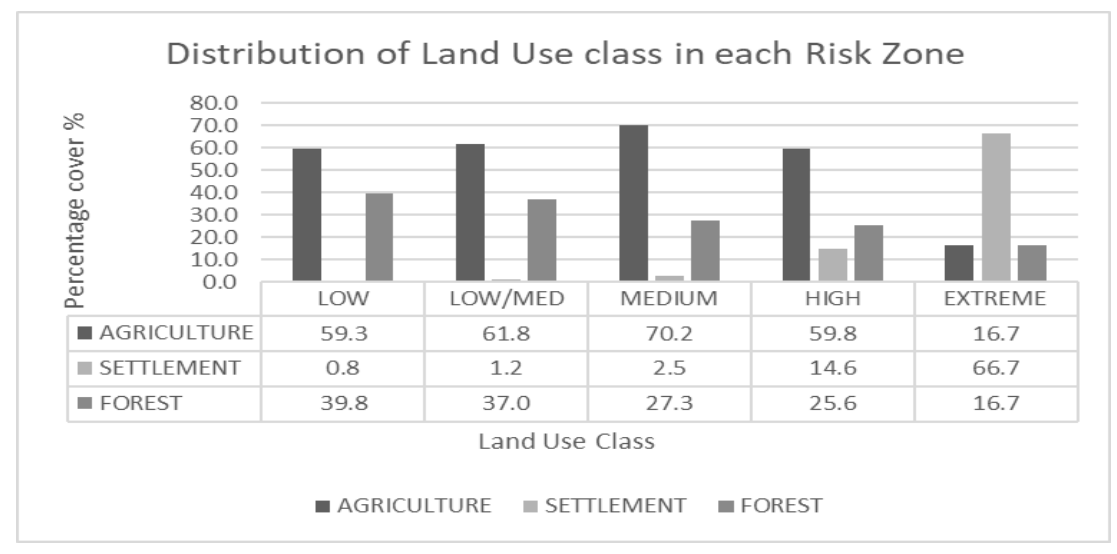

Fig. 5. Percentage distribution of land use type against each hazard level

In Fig. 6, we observe how the individual land use probabilities influence the risk levels. In the case of agriculture land use, as the probability increases, there would be a reduction in the areas with lower disaster risks. Whereas medium risk areas would increase, and the high-risk areas remain constant. For settlement land use probability, settlement land use expansion tends to increase the high- risk areas, while low and medium risk areas gradually reduce. However, for forest land use probability, the changes in the level of risk are negligible. 


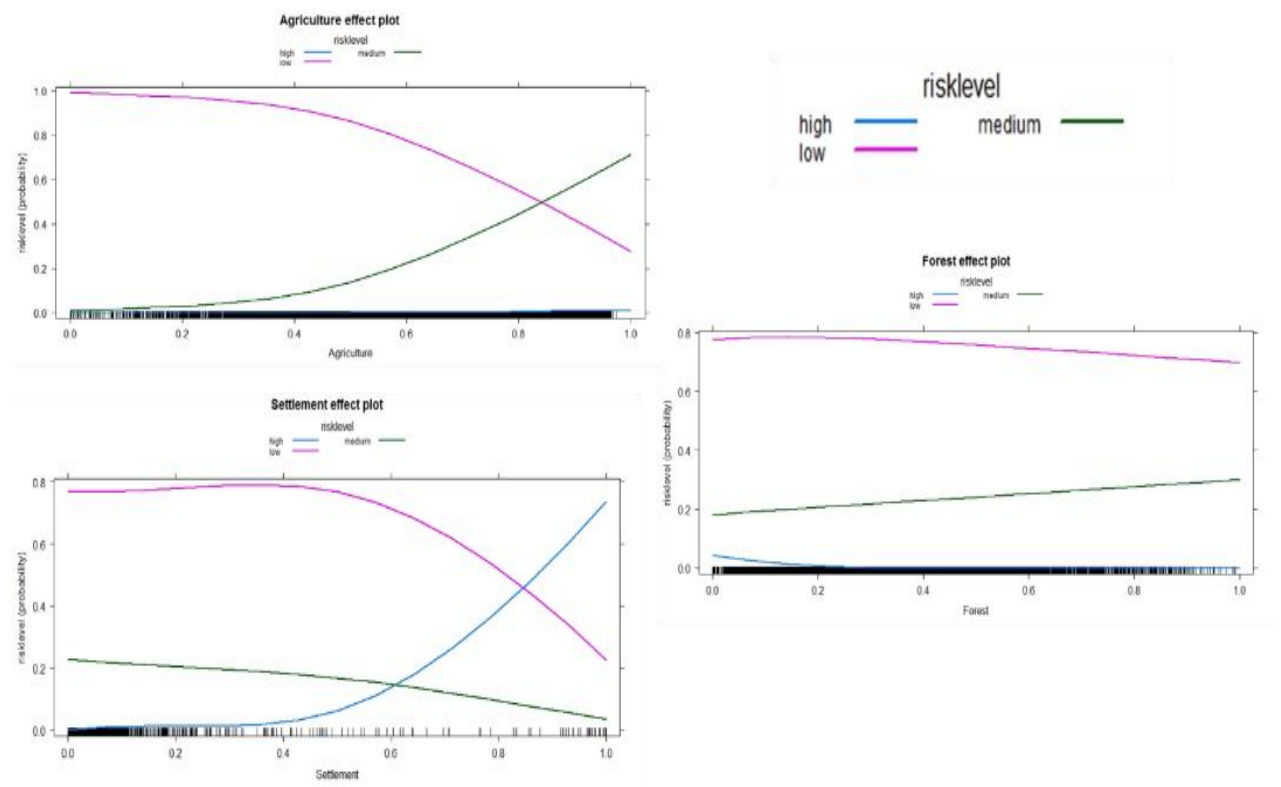

Fig. 6. The effects of the probability of each land use type on risk levels

\section{CONCLUSIONS}

The objective of the study is to determine the drivers of land use change and the effects of the probability of each LULC change on flood risk levels. This study successfully confirmed the drivers of land use and the effects of land use on each risk level. The results showed that the drivers of land use changes in Nigeria were the gross regional product, average temperature, migration and population density, in which the gross regional product and migration had the highest impacts on land use change. We further analysed how the drivers of land use change in conjunction with the likelihood of each changing land use class impacted on the level of risks in Nigeria. The results show that settlement land use changes increase the high-risk zones. In contrast, agriculture land use increases the medium risks areas and forest land use did not significantly influence the level of risks. The evidence from the research suggests that the use of variables of diverse characteristics is crucial for understanding the implications of the social, climatic, economic and demographics variables directly impacts land use changes and indirectly on disaster risks conditions (Fujiki \& Renard, 2018). Therefore, this study highlights the relevance of developing and promoting effective land use management systems, through a consideration of natural and social systems for both land use changes and existing disasters which can enable the promotion of disaster resilience and achieve a sustainable society (Klemešová et al., 2014). The study result advocates for the introduction and implementation of proper policies that regulate land use conversion and promotes sustainable land use management. The methodology applied in this study showcases the importance of the application and consideration of different techniques in proffering solutions to land use and disaster management in Nigeria, as it enables the compilation of vital information from different sources in achieving the desired goals. 


\section{REFERENCES}

Bashir, O., O., Oludare H., A., Johnson O., O., \& Aloysius, B. (2012). Floods of Fury in Nigerian Cities. Journal of Sustainable Development. https://doi.org/10.5539/jsd.v5n7p69

Fujiki, K., \& Renard, F. (2018). A geographic analysis of post-disaster social impacts on a municipal scale - A case study of a potential major flood in the paris region (France). Geographia Technica. https://doi.org/10.21163/GT_2018.132.03

Furtună, P., \& Holobâcă, I. H. (2013). Forest fires study using remote sensing and meteorological indicators. Study case. Geographia Technica, 18(2), 23-37.

Khan, M. M. H., Bryceson, I., Kolivras, K. N., Faruque, F., Rahman, M. M., \& Haque, U. (2014). Natural disasters and land-use/land-cover change in the southwest coastal areas of Bangladesh. Regional Environmental Change, 15(2), 241-250. https://doi.org/10.1007/s10113-014-0642-8

Kim, I., \& Heung, C. (2016). Development of integrated modeling framework of land use changes and ecosystem services in mountainous watersheds, (October 1980).

Klemešová, K., Kolář, M., \& Andráško, I. (2014). Using gis in the flood management - flood maps (Troubky, Czech Republic). Geographia Technica, 9(2), 44-53.

Meyer, W. B., \& Turner, B. L. (2003). Human Population Growth and Global Land-Use/Cover Change. Annual Review of Ecology and Systematics. https://doi.org/10.1146/annurev.es.23.110192.000351

Oladokun, V. O., \& Proverbs, D. (2016). Flood risk management in Nigeria: A review of the challenges and opportunities. International Journal of Safety and Security Engineering, 6(3), 485-497. https://doi.org/10.2495/SAFE-V6-N3-485-497

Olorunfemi, F. B., \& Adebimpe, R. U. (2011). Sustainable Disaster Risk Reduction in Nigeria: Lessons for Developing Countries. African Research Review. https://doi.org/10.4314/afrrev.v2i2.41050

Peter, E., Samuel, D., \& Olatunji, B. (2012). Land Use Change Modelling In Developing Countries: Issues And Prospects. International Journal of Geography and Geology, 1(1), $23-41$.

Suwarno, Sutomo, \& Aditama, M. R. (2019). The analysis of the landslide vulnerability sub watersheds arus in Banyumas regency. Geographia Technica. https://doi.org/10.21163/GT_2019.142.10

UNISDR, UNEP, \& Umvoto Africa. (2004). Environmental Protection \& Disaster Risk Reduction A Community Leader's Guide, Volume 2, Issue 2. UN/ISDR Africa Educational Series 